\title{
The Value Of Marketing Expertise
}

\author{
Pasa M, Shugan SM
}

Management Science

42 (3): 370-388 Mar 1996

\section{Abstract:}

This paper has three objectives: (1) to construct a theoretical model that aids in evaluating marketing expertise, (2) to use that theoretical model to identify factors influencing the Value of marketing expertise, and (3) to empirically test the model by observing how different market conditions influence whether companies emphasize marketing expertise. We accomplish these objectives as follows.

First, we use decision theory to find an expression far the expected value of marketing expertise. We do not use decision-analysis in the normative tradition. Nor do we assume that firms actually use formal decision-analysis. Rather, we assume that firms are rational and that decision theory describes their actions. Given that assumption, we predict how firms should evaluate marketing. Here, marketing expertise helps a firm make better marketing decisions (at least on average). Hence, the value of marketing expertise increases as marketing decisions become more important.

Second, consistent with decision theory, we predict that marketing decisions become more important with increases in the instability of the marketing environment (i.e., predictability), the profit impact of marketing decisions (i.e., opportunity profit), and the loss from marketing mistakes (i.e., potential loss).

Third, we construct empirical measures of our theoretical constructs with data from 592 firms. Our empirical results are consistent with our predictions and reveal factors influencing the value of marketing expertise. For example, greater market instability and market presence increase the value of marketing expertise, while larger organization size, organization instability, 


\title{
The Value of Marketing Expertise
}

\author{
Mehmet Paşa* • Steven M. Shugan \\ McKinsey \& Company, Istanbul, Turkey \\ College of Business Administration, The University of Florida, Gainesville, Florida 32611-2017
}

\begin{abstract}
$\mathrm{T}$ his paper has three objectives: (1) to construct a theoretical model that aids in evaluating marketing expertise, (2) to use that theoretical model to identify factors influencing the value of marketing expertise, and (3) to empirically test the model by observing how different market conditions influence whether companies emphasize marketing expertise. We accomplish these objectives as follows.

First, we use decision theory to find an expression for the expected value of marketing expertise. We do not use decision-analysis in the normative tradition. Nor do we assume that firms actually use formal decision-analysis. Rather, we assume that firms are rational and that decision theory describes their actions. Given that assumption, we predict how firms should evaluate marketing. Here, marketing expertise helps a firm make better marketing decisions (at least on average). Hence, the value of marketing expertise increases as marketing decisions become more important.

Second, consistent with decision theory, we predict that marketing decisions become more important with increases in the instability of the marketing environment (i.e., predictability), the profit impact of marketing decisions (i.e., opportunity profit), and the loss from marketing mistakes (i.e., potential loss).

Third, we construct empirical measures of our theoretical constructs with data from 592 firms. Our empirical results are consistent with our predictions and reveal factors influencing the value of marketing expertise. For example, greater market instability and market presence increase the value of marketing expertise, while larger organization size, organization instability, and competition decrease its value.

(Marketing; Value; Expertise; Decision Analysis)
\end{abstract}

\section{Introduction}

Marketing's role has evolved from simply enhancing demand for the factory's current output to being a critical part of the strategic planning process. Using market information, defining market segments, and target marketing are now crucial components of the business plan (Webster 1988). Marketing expertise helps a firm make better marketing decisions that can improve the performance and profitability of the firm.

* This work was completed in full before the author joined McKinsey \& Company.
Marketing expertise is an important skill required by every firm (Kinnear and Bernhardt 1986, McCarthy and Perreault 1984). Marketing expertise alone, however, is insufficient. Firms require many skills, including production and financial expertise (Aaker 1988, 1989). Although firms want expertise in many areas, acquiring these skills is expensive. Emphasizing marketing expertise may, by definition, deemphasize other skills. To effectively allocate resources, the firms must find the relative and marginal value of marketing expertise (Deshpande and Parasuraman 1984). Thus, making strategic decisions (Cook 1983; Day and Wensley 1983,1988 ) requires judgments about the value of marketing expertise. 
Some firms place less value on marketing expertise. This evaluation appears to depend on firm and market factors ${ }^{1}$ (Houston 1986, Kohli and Jaworski 1990, Levitt 1983). A recent Forbes magazine article (Simon and Button 1990) provides a clear example of the contrast that exists across industries:

\footnotetext{
"The heart and soul of competing is knowing how to appeal to your customers. If you can't provide the products they really want, you won't succeed."

Donald Petersen, Chairperson, Ford Motor Company

"Companies have to improve not only the quality of their products but the quality of the process by which their products are designed and built . . . Companies and universities gave very little attention to the technology of manufacturing."

Frank Schrontz, Chairperson, Boeing Corporation
}

Ford Motor Company espouses marketing expertise, while Boeing Corporation stresses production expertise. Unfortunately, as Kohli and Jaworski (1990) report, no theory exists for explaining this distinction and predicting which firm and market factors should influence the relative value of marketing expertise. Possible factors are numerous, ranging from industry characteristics (such as concentration and scale economies) to firm size and productivity. Capon et al. (1990) list over 175 factors considered by 320 different studies as determinants of financial performance. Moreover, there is no consensus on predicted relationships. For example, in their survey, Kohli and Jaworski (1990) find that marketing is more valuable in industries with greater competition. However, greater competition also requires cost cutting and more efficient manufacturing (Levitt 1983), which makes production more valuable. Without a theoretical model it is difficult to sort out the many factors and reconcile the different views.

A theoretical model or framework could identify the factors that determine the relative priority of marketing expertise. Identification and comprehension of these factors are important (Narver and Slater 1990). They are the foundation of any strategic plan. In this paper, we

\footnotetext{
${ }^{1}$ Note that the impact of firm and market factors on the success of various marketing tactics is well recognized in the literature (Boulding and Staelin 1990, Gatignon et al. 1990). However, their impact on the effectiveness of marketing expertise is more controversial.
}

provide a theoretical and empirical model for approaching this problem.

This paper has three objectives. First, we want to construct a theoretical model that aids in evaluating marketing expertise. Second, we want to use that theoretical model to identify factors influencing the value of marketing expertise. Third, we want to empirically test the model.

Our model provides guidelines about when a firm should invest in marketing expertise. We identify some conditions that increase the value of marketing expertise. Our model helps a firm analyze whether it should invest more or less in marketing expertise given its current environmental conditions. This analysis is especially critical when the environment is changing; the future may require rethinking the role of different functions.

To provide a framework for finding the value of marketing expertise, we rely on the well-established area of decision analysis (Bernoulli 1738, Eliashberg and Winkler 1981, Keeney 1982, Luce and Raffia 1957, Schlaifer 1959). We do not, however, use decision analysis in the normative tradition (Eliashberg and Hauser 1985) of prescribing behavior. We do not assume that firms actually use formal decision analysis. Rather, we allow firms to be rational profit maximizers. We only use decision theory to describe their actions. Given that assumption, we predict how firms should evaluate marketing expertise. Understanding that marketing deals with information, we can link the value of marketing expertise to the expected value of information using a decision-theoretical model.

Section 2 presents the model and derives a theoretical expression for the value of marketing expertise. We use decision theory qualitatively for directional effects rather than computing specific dollar values. For example, we show that the value of marketing expertise increases as market instability increases.

Section 3 translates this expression to specific observable firm and market factors. This task is difficult because we want specific measures beyond qualitative factors. Here, decision theory provides less guidance. Given this problem, we proceed in two phases. First, we take the mathematical expression for the expected value of perfect marketing expertise and derive qualitative implications. These become our propositions. Second, 
we determine observable measures for those ramifications. Here, we use measures and relationships suggested by micro-economic theory (e.g., competition decreases profits) and strategy literature (e.g., market advantage means higher earnings). These become our hypotheses.

Section 4 empirically tests our hypotheses using data from 592 different firms. Our empirical analysis shows that certain factors do make marketing expertise more valuable to a firm. Greater market instability and market presence increase the value of marketing expertise while larger organization size, organization instability, and competition decrease its value.

The paper ends with managerial implications and suggestions for future research.

\section{Theory and Model}

We define marketing expertise as the ability to make better marketing decisions. Of course, decision-making is only one part of marketing management (GomezMejia et al. 1985, Steers et al. 1985, Whitley 1985). However, decision-making is an important part of management (Bunn 1984, Keeney 1982, Winkler 1972, Urban and Star 1991).

The literature often emphasizes improving decisions with the use of data. Although data are important, data often require interpretation. In fact, the two are inseparable. For example, consider medical expertise. A physician examines a patient collecting both physical and verbal data concerning the patient's condition. Medical expertise allows the physician to ignore some data while emphasizing other data to form a diagnosis. Without medical expertise, we could be misled by obvious symptoms and could overlook less obvious, but critical, information necessary for a correct diagnosis.

We argue that marketing expertise creates better decisions by providing interpreted market data. Hence, expertise creates information from data by adding interpretation. Beyond interpreting data, expertise also filters information and determines which information to collect. Hence, as marketing information becomes more important for firm decisions, the value of marketing expertise increases. We conclude that measuring the value of market information also provides a measure of the value of marketing expertise.
If the value of market information measures the value of marketing expertise, then decision analysis provides an established method for measuring the value of marketing expertise. Decision analysis (Bernoulli 1738, Bunn 1984, Chernoff and Moses 1959, Keeney 1982, Luce and Raffia 1957, Raiffa 1968, Schlaifer 1959, Winkler and Hays 1975, Winkler 1972) is one of few theories for precisely defining the value of market information. Although this definition is limited to decision-making, the definition is precise. The value of marketing information is the difference between the expected value of decision outcomes with and without that information. The value of information or expertise becomes the incremental expected benefit that expertise provides. So the expected impact of marketing information on firm decision-making determines the value of marketing expertise.

Classical decision analysis assumes that data resolve or lessen uncertainty. We assume data alone are equivocal. Determining whether a new product will succeed, for example, requires marketing expertise allowing interpretation of market research data. By requiring expertise, we allow two firms facing identical market data to take different strategies based solely on interpretation or available expertise. Marketing information is more valuable when it allows the firm to make better decisions. Marketing information is less valuable when it has little impact on the firm's decisions.

Consider a simple example. Consider taking a particular marketing strategy in an uncertain world that could be in two states: receptive or unreceptive to the strategy. Although we expect the world is receptive, we may be mistaken, and the strategy could be wrong. The following formula provides the incremental expected benefit of knowing the true state-of-the-world (i.e., perfect marketing expertise).

$$
\begin{gathered}
\text { value of } \\
\text { marketing } \\
\text { expertise }
\end{gathered}=\begin{gathered}
\text { probability } \\
\text { of being } \\
\text { mistaken }
\end{gathered} \times\left[\begin{array}{cc}
\text { profit from } & \text { outcome from } \\
\text { best alternate }- & \text { wrong } \\
\text { strategy } & \text { strategy }
\end{array}\right] \text {. }
$$

Here, the value of marketing expertise depends on three factors: (1) the probability of a mistake; (2) the profit impact from alternate strategies, i.e., strategies not taken without marketing expertise; and ( 3 ) the potential loss from a mistake. Moreover, the value of nonmarketing expertise would be influenced by similar factors 
such as the loss from an incorrect production strategy. In sum, we equate the value of marketing expertise to the value of market information.

Our reasoning is consistent with the contemporary view that marketing provides the primary interface between the market and the firm in an exchange process (Bagozzi 1975; Kotler 1972, 1984; Houston 1986). However, we make a fundamental modification to this idea. Rather than considering the complete role of marketing, perhaps an impossible task, we focus on the management or decision-making functions involved in this exchange. We model these decisions using decision theory. Decision theory provides a tractable model with precise and testable implications.

Within this model, firms decide among different marketing strategies. The decision uses specific marketing expertise or information. In our model, a firm can invest only in two types of expertise, marketing and nonmarketing. To some extent, nonmarketing expertise is an opportunity cost for marketing expertise (i.e., to invest in marketing expertise, the firm forgoes some investment in nonmarketing expertise). Marketing experts, for example, can have a greater or smaller degree of influence on top corporate decisions. This is true for every type of expertise (e.g., legal, ecological, etc.).

Within a decision-theoretic model, information partitions the strategy space (Marschak and Radner 1972). Hence, marketing information is valuable only for choosing a strategy. This is a simplification. Marketing information may be valuable for purposes other than choosing a strategy. For example, marketing information can help managers gain the critical internal support and consensus that are necessary for the success of a marketing strategy.

Here, we have a set $\Gamma_{\imath}$ of marketing strategies (Marschak and Radner 1972). We define the strategy space vector $\iota$ as follows.

$$
\iota=\left\langle\iota_{1}, \iota_{2}, \iota_{3}, \iota_{4}, \ldots\right\rangle, \text { where }
$$

$\iota=$ the vector of marketing strategies,

$\iota_{i}=$ marketing strategy $i, i \in \Gamma_{\iota}$.

Each marketing strategy is complex and includes many individual decisions. For example, $\iota_{1}$ could be a shrink/niche strategy, $\iota_{2}$ could be a market growth strategy, and $\iota_{3}$ could be a hold/reposition strategy. Each strategy implies different decisions regarding new product introductions, advertising, distribution, pricing, sales force deployment, and so on. The appropriate strategy depends on the true state-of-the-world. Different states often favor one strategy over another. Marketing expertise seeks to determine the true state by interpreting data on buyer preferences, buyer perceptions, past competitive actions, and so on. Marketing expertise, therefore, can change the firm's subjective probability of particular outcomes.

For nonmarketing expertise, we have a set $\Gamma_{\psi}$ of nonmarketing strategies. Obviously, this strategy space includes strategies in many different areas involving production, finance, personnel, and so on.

$$
\psi=\left\langle\psi_{1}, \psi_{2}, \psi_{3}, \psi_{4}, \ldots\right\rangle \text {, where }
$$

$\psi=$ the vector of nonmarketing strategies,

$\psi_{k}=$ nonmarketing strategy $k, k \in \Gamma_{\psi}$.

Sometimes marketing and nonmarketing activities are difficult to separate. Producing a particular product design may involve knowledge of both the market and the firm's manufacturing capabilities, suggesting a multidisciplinary approach (Child 1977, Duncan 1979, Mintzberg 1979, Randolph and Dess 1984). However, empirical experience (Coggin 1974, Daft and Steers 1986, Duncan 1979, Springmier 1982) is consistent with having a distinct set $\psi$. Clear functional areas still exist in most organizations.

With current marketing expertise, the firm chooses a corporate strategy $\left\langle\iota_{i}, \psi_{k}\right\rangle$. The choice depends on the firm's beliefs regarding the state-of-the-world. ${ }^{2}$ To simplify the problem, assume different state spaces for each class of strategies, i.e., $\iota$ and $\psi$. See equations (3) and (4).

$$
\begin{gathered}
I=\left\langle I_{1}, I_{2}, I_{3}, I_{4}, \ldots\right\rangle, \\
\Psi=\left\langle\Psi_{1}, \Psi_{2}, \Psi_{3}, \Psi_{4}, \ldots\right\rangle, \quad \text { where }
\end{gathered}
$$

$I=\iota$-states representing state variables affecting profit from marketing strategies,

$I_{h}=\iota$-state $h, h \in \Phi_{I}$,

$\Psi=\psi$-states representing state variables affecting profits from nonmarketing strategies,

$$
\Psi_{n}=\psi \text {-state } n, n \in \Phi_{\Psi} \text {. }
$$

${ }^{2}$ Schlaifer (1959) calls a state-of-the-world an event, and Raiffa (1968) calls it a state. 
A state-of-the-world is comprehensive and reflects many components, ${ }^{3}$ and $I_{h}$ represents $\iota$-state $h$. Suppose, for example, a firm's decision space consists of different designs for a new product, and $\iota_{i}$ corresponds to launching design $i$. Then, state $I_{h}$ corresponds to buyers who are very receptive to design $i$, while other states correspond to buyers who are less receptive to design $i$. Similarly, $\psi_{k}$ might correspond to production scheduling strategy $k$, and $\Psi_{n}$ corresponds to a state-of-the-world $n$ where scheduling strategy $k$ works better or worse than other states of the world.

The world, of course, has only one true state. Perfect marketing expertise reveals which $I_{h}$ is the true state. Let $I_{T}$ be the true $\iota$-state and let $\Psi_{T}$ be the true $\psi$-state. More marketing expertise places a higher probability on correctly identifying the true $\iota$-state. More nonmarketing expertise places a higher probability on correctly identifying the true $\psi$-state.

Note the relationship between the strategy space and the state-of-the-world. Given a particular state-of-the world $\left\langle I_{h}, \Psi_{n}\right\rangle$, and a particular strategy $\left\langle\iota_{i}, \psi_{k}\right\rangle$, the firm would receive a payoff, $\Pi\left(\left\langle\iota_{i}, \psi_{k}\right\rangle,\left\langle I_{h}, \Psi_{n}\right\rangle\right)$. We do not specify an explicit form for the firm's profit function. Nonetheless, we note that interaction effects between marketing and nonmarketing strategies can be important (Eliashberg and Steinberg 1987, Hauser and Clausing 1988, Shapiro 1988, Zirger and Madique 1990), and should be explored in future studies. However, incorporating these interactions adds little to the objective of our analysis and greatly complicates the notation.

The primary objective, in decision analysis, is to maximize the expected payoff. ${ }^{4}$ Payoffs, of course, depend

\footnotetext{
${ }^{3}$ The states-of-the-world in each state space are assumed to be collectively exhaustive (i.e., one of the states-of-the-world is bound to occur). For tractability, we make a simplification and assume discrete state sets in each state space.

${ }^{4}$ In the literature, this is known as maximizing expected monetary value (EMV), as introduced by Schlaifer (1959). Another objective can be maximizing expected utility, where monetary values are replaced with the corresponding utilities of the decision maker. The solution stays the same as long as the conditional utility is linear in money (i.e., risk neutral). In cases of nonlinear utility (i.e., risk averse or risk lover), certainty monetary equivalent (CME) can be used instead of utility. This allows two firms (e.g., a small firm and a large firm) with different levels of risk aversion to choose different strategies when faced with the same prospect. Eliashberg and Chatterjee (1985) suggest the use of group utility functions.
}

on the true state-of-the-world. Having expertise is equivalent to having information or knowledge about the true state. Perfect expertise, for example, would reveal the actual state-of-the-world.

If we expect, for example, that the world is receptive to a niche strategy and we are wrong, our payoff is lower. Suppose marketing expertise reveals that the true state is more receptive to a growth strategy. The value of marketing expertise is the difference between the payoffs from a growth strategy and a niche strategy (in a world favoring growth). Multiplying the difference in payoffs by the probability that the true state favors a growth strategy yields the expected value of marketing expertise.

We define marketing expertise as the ability to create, and correctly interpret, information about $I_{h}$. That information might include market research, past trends in sales, and likely competitive reactions. Marketing expertise increases the firm's subjective probability for the true state-of-the-world. We see that marketing expertise affects the firm's expectations.

The firm has an expectation regarding the likelihood that each state $I_{h}$ is true. We represent this likelihood with a probability $p_{I}\left(I_{h}\right)$. Remember there is no true probability. One state is true with certainty. The probability $p_{I}\left(I_{h}\right)$ reflects the firm's beliefs about which state is true. Hence, the firm believes state $I_{h}$ is true with probability $p_{I}\left(I_{h}\right)$. If the firm takes action $\iota_{i}$, it expects payoff $\Pi_{\iota}\left(\iota_{i}, I_{h}\right)$ with probability $p_{I}\left(I_{h}\right)$. Hence, a risk-neutral firm chooses the strategy $\iota_{*}$ that maximizes expected profits as shown in equation (5);

$$
\iota_{*}=\underset{\iota_{1}, \iota_{2}, \ldots}{\operatorname{argmax}} \sum_{h \in \Phi_{l}} p_{l}\left(I_{h}\right) \Pi_{\iota}\left(\iota_{i}, I_{h}\right), \quad \text { where }
$$

$\iota_{*}=$ the optimal marketing strategy given current marketing expertise,

$p_{I}\left(I_{h}\right)=$ the probability of state $I_{h}$, reflecting the firm's expectations given current marketing expertise.

Equation (6) defines $\Pi_{t}\left(\iota_{*}\right)$ :

$$
\Pi_{\iota}\left(\iota_{*}\right)=\sum_{h \in \Phi_{l}} p_{I}\left(I_{h}\right) \Pi_{t}\left(\iota_{*}, I_{h}\right), \quad \text { where }
$$

$\Pi_{\iota}\left(\iota_{*}\right)=$ the expected payoff of optimal marketing strategy given current marketing expertise.

Here, $\Pi_{\iota}\left(\iota_{*}\right)$ represents the firm's expected payoff given the current beliefs of the firm, $p_{I}\left(I_{h}\right)$, with current 
marketing expertise. Although the decision-analysis model considers a stochastic world, only one outcome occurs. The beliefs, depicted by $p_{I}\left(I_{h}\right)$, only reflect the uncertainty held by the decision-maker.

Hence, despite $p_{I}\left(I_{h}\right)$, the strategy $\iota_{*}$ will, with certainty, lead to a precise payoff $\Pi_{\iota}\left(\iota_{*}, I_{T}\right)$. In fact, every strategy $\iota_{i}$ leads to a precise outcome. Equation (7) defines the strategy $\iota^{*}\left(I_{h}\right)$ that maximizes the payoff for any given state $I_{h}$ :

$$
\iota^{*}\left(I_{h}\right)=\underset{j}{\operatorname{argmax}} \Pi_{\iota}\left(\iota_{j}, I_{h}\right), \quad \text { where }
$$

$\iota^{*}\left(I_{h}\right)=$ the optimal marketing strategy given the state $I_{h}$.

We define perfect marketing expertise as the ability to detect the true $\iota$-state, ${ }^{5} I_{T}$. Of course, we could define imperfect expertise that leads to improved decisions with less than perfect knowledge about $I_{T}$. Using imperfect expertise greatly complicates the development while adding little insight. Moreover, perfect marketing expertise allows us to benchmark the value of imperfect expertise.

If the firm acquires perfect marketing expertise, it will know the true state-of-the-world $I_{T}$. It can then choose strategy $\iota^{*}\left(I_{T}\right)$ and receive the payoff $\Pi_{\iota}\left(\iota^{*}\left(I_{T}\right), I_{T}\right)$. Now the actual value of marketing expertise is the difference in payoffs between perfect and current expertise given the true state. So the value of marketing expertise is $\Pi_{\iota}\left(\iota^{*}\left(I_{T}\right), I_{T}\right)-\Pi_{\iota}\left(\iota_{*}, I_{T}\right)$.

Unfortunately, computing this quantity is impossible because the firm makes a decision whether to acquire marketing expertise, before learning the true state $I_{T}$. The firm only learns $I_{T}$ after acquiring perfect marketing expertise. This creates a dilemma. Although firms cannot compute the value of marketing expertise, they can compute the expected value of marketing expertise. Using the firm's expectations before acquiring marketing expertise, i.e., $p_{I}\left(I_{h}\right)$, they compute the likelihood that expertise identifies each state $I_{h}$ as the true state $I_{T}$. The expected payoff of perfect marketing expertise follows. See equation (8):

\footnotetext{
${ }^{5}$ In this framework, perfect expertise means having perfect information. Therefore, the following development parallels the concept of expected value of perfect information (EVPI) (Schlaifer 1959).
}

$$
\Pi_{\iota}=\sum_{h \in \Phi_{l}} \rho_{l}\left(I_{h}\right) \Pi_{\iota}\left(\iota^{*}\left(I_{h}\right), I_{h}\right), \quad \text { where }
$$

$\Pi_{\iota}=$ the expected payoff given perfect marketing expertise. Equation (9) provides the expected value of marketing:

EVME $=\sum_{h \in \Phi_{l}} p_{I}\left(I_{h}\right)\left[\Pi_{\iota}\left(\iota^{*}\left(I_{h}\right), I_{h}\right)-\Pi_{\iota}\left(\iota_{*}, I_{h}\right)\right], \quad$ where

$\mathrm{EVME}=$ the expected value of perfect marketing expertise.

Equation (9) provides a theoretical measure for the expected value of marketing expertise. Note that we deviate slightly from the decision-analysis literature by introducing the concept of expertise. Within the decisionanalysis model, only information is important. Here, we consider information as consisting of both the data and the ability to interpret those data. By adding the notion of interpretation, we allow two firms facing identical data to take different strategies based solely on managerial judgment.

We conclude this section with two comments about the expected value of marketing expertise. First, EVME represents perfect expertise in marketing. In reality, we may never find perfect expertise. Like most investments, investment in expertise will exhibit diminishing marginal returns. It is too costly to obtain perfect expertise. Obviously, imperfect marketing expertise might lead to strategies with outcomes less desirable than $\Pi_{t}\left(\iota^{*}\left(I_{T}\right), I_{T}\right)$, but still more desirable than $\Pi_{c}\left(\iota_{*}\right)$. Here, it is important to place conditions on the probability distribution $p_{I}$ so that the expected value of the strategy increases as expertise increases. To simplify the exposition, we only consider the case of complete expertise.

Second, EVME will be difficult to measure without experimentation. Fortunately, we do not need to measure it directly. Our objective is to find the factors increasing or decreasing the expected value of marketing expertise. The definition of $\operatorname{EV}_{\iota}\left(\iota_{*}\right)$ helps us identify these factors.

\section{Propositions and Hypotheses}

Equation (9) provides a theoretical measure for the expected value of perfect marketing expertise. We know 
from equation (9) that, ceteris paribus, as $\Pi_{i}\left(\iota_{*}\right)$ decreases, the expected value of marketing expertise increases. Substituting from equation (6) and equation (8) into equation (9), and rearranging, we obtain equation (10) for the expected value of perfect marketing expertise:

$$
\operatorname{EVME}=\sum_{h \in \Phi_{l}} p_{I}\left(I_{h}\right) \Pi_{\iota}\left(\iota^{*}\left(I_{h}\right), I_{h}\right)\left[1-\frac{\Pi_{\iota}\left(\iota_{*}, I_{h}\right)}{\Pi_{\iota}\left(\iota^{*}\left(I_{h}\right), I_{h}\right)}\right] .
$$

However, it is more meaningful to consider the expected value of perfect marketing expertise after adjusting for the scale of operations. ${ }^{6}$ Equation (11) provides the expected value of perfect marketing expertise per unit:

$$
\begin{aligned}
\text { EVMEU }= & \sum_{h \in \Phi_{l}} p_{I}\left(I_{h}\right)\left[\frac{\Pi_{\iota}\left(\iota^{*}\left(I_{h}\right), I_{h}\right)}{S}\right] \\
& \times\left[1-\frac{\Pi_{\iota}\left(\iota_{*}, I_{h}\right)}{\Pi_{\iota}\left(\iota^{*}\left(I_{h}\right), I_{h}\right)}\right] .
\end{aligned}
$$

Similarly, Equation (12) provides the expected value of perfect nonmarketing expertise per unit:

$$
\begin{aligned}
\text { EVNEU }= & \sum_{n \in \Phi_{\psi}} p_{\Psi}\left(\Psi_{n}\right)\left[\frac{\Pi_{\psi}\left(\psi^{*}\left(\Psi_{n}\right), \Psi_{n}\right)}{S}\right] \\
& \times\left[1-\frac{\Pi_{\psi}\left(\psi_{*}, \Psi_{n}\right)}{\Pi_{\psi}\left(\psi^{*}\left(\Psi_{n}\right), \Psi_{n}\right)}\right], \text { where }
\end{aligned}
$$

EVNEU $=$ the expected value of perfect nonmarketing expertise per unit,

$\psi_{*}=$ the optimal nonmarketing strategy given current nonmarketing expertise,

$P_{\Psi}\left(\Psi_{n}\right)=$ the probability of $\Psi$-state $n$ that reflects the firm's expectations given current non-marketing expertise,

$\Pi_{\psi}\left(\psi_{k}, \Psi_{n}\right)=$ the payoff from nonmarketing strategy $\psi_{k}$ in state $\Psi_{n}$

\footnotetext{
${ }^{6}$ The decision theoretic framework looks at the Expected Value of Perfect Marketing Expertise in terms of its absolute magnitude. Thus, the Expected Value of Perfect Marketing Expertise increases as the scale of operations increases. If a firm merely doubled in size (sales) while maintaining the same profitability (profit/sales), the Expected Value of Perfect Marketing Expertise would double. Scaling by sales avoids this problem (Associate Editor).
}

$\psi^{*}\left(\Psi_{n}\right)=$ the optimal nonmarketing strategy given the true state as $\Psi_{n}$.

Equation (11) provides three conditions affecting the expected value of perfect marketing expertise scaled by sales, EVMEU:

(1) When $p_{I}\left(I_{h}\right)$ approaches one for some state $h$, EVMEU decreases. ${ }^{?}$

(2) When $\Pi_{\iota}\left(\iota^{*}\left(I_{h}\right), I_{h}\right) / S$ increases, EVMEU increases.

(3) When $\Pi_{\iota}\left(\iota_{*}, I_{h}\right) / \Pi_{\iota}\left(\iota^{*}\left(I_{h}\right), I_{h}\right)$ decreases, EVMEU increases.

Equation (11) provides us with three propositions. Each proposition suggests a testable hypothesis. Note that the relationships, given in equation (11), are multivariate. Therefore, each condition is true, ceteris paribus (i.e., each condition is true holding all other influencing variables constant). We now discuss these propositions and the corresponding hypotheses.

To test the propositions, we must translate these theoretical constructs into measurable variables. This task is difficult because decision theory provides little guidance concerning what factors should increase or decrease $p_{I}\left(I_{h}\right)$.

Given this problem, we proceed in two phases. First, we take each of the three mathematical conditions for the EVMEU and derive a corresponding qualitative ramification. These become our propositions. Second, we find observable measures for those ramifications. Here, we use measures and relationships suggested by micro-economic theory (e.g., competition decreases profits) and the strategy literature (e.g., market advantage spawns higher earnings) to create testable hypotheses. We hope our two-phase approach begins to address this difficult problem.

Consider condition 1 . This condition says that when the market is turbulent (e.g., many possible $\iota$-states) and forecasting is difficult (e.g., many equally likely $\iota$ states), there is a greater need for market expertise. Of course, forecasting is simpler when the market is unchanging. For example, suppose the market exists in

\footnotetext{
${ }^{7}$ Condition 3 follows from the fact that when the probability of some state approaches one, the optimal strategy with current expertise becomes identical to the optimal strategy with perfect expertise (i.e., when $p_{l}\left(I_{k}\right)=1$ for some $k \in \Phi_{l, \iota_{*}} \equiv \iota_{* *}\left(I_{k}\right)$ and $\left.\operatorname{EV} \iota\left(\iota_{*}\right) / S=0\right)$. See the appendix for proof of Condition 1 .
} 
only one state, i.e., $p_{I}\left(l_{1}\right)=1$. This state may reflect almost constant demand for the firm's products. Here, the state space is predictable because the firm expects only one state. Marketing expertise has no value because expertise has little to reveal. Hence, as the stability of the market increases, the uncertainty of the managers decreases (i.e., some probabilities approach zero). ${ }^{8}$ This lowers the expected value of marketing expertise. Conversely, increasing market instability, increases EVMEU. Proposition 1 follows.

PROPOSITION 1. Marketing expertise is more valuable when market instability increases.

There are many indicators of market instability. Often, market stability simplifies prediction while rapid change makes prediction more difficult. Very stable product categories, for example, reduce instability by lessening the chance of radical change. New products, however, create many possible outcomes (many new $t$ states), and these outcomes are less predictable. New products can shift demand for existing products, change purchasing patterns, transpose category size, and encourage additional innovations. Moreover, observing new products also suggests exogenous changes in the market such as new firm entry, changing demographics, changing customer needs, and new buyers in the market.

In markets with many new products, predicting sales is more difficult and complex (Urban and Hauser 1980) because past trends no longer predict the future. Buyers may shift to new products. This shift, however, is difficult to predict because many buyers may be unaware of new products and awareness may change over time. Moreover, before shifts take place, additional new products may enter and again change the dynamics of the market.

Most marketing textbooks (e.g., Urban and Hauser 1980) note that forecasting (i.e., $\iota$-states) in markets with new products is far more difficult because of these factors. New products create, and sometimes reflect, changing markets. Hence, regardless of whether new products cause or follow market change, the need for marketing expertise should increase.

\footnotetext{
${ }^{8}$ Note that uncertainty is a state of managers' minds, and it is a func-
} tion of the environment and its interpretation (Reviewer B).
Finally, we control for the scale of operation, because some firms may have a greater absolute need for marketing expertise simply because of their large scale of operations. Hypothesis 1a follows:

HYPOTHESIS 1A. Controlling for the scale of operations, firms facing high market instability (created or reflected by new products), have a greater need for marketing expertise.

Equation (12) implies that, controlling for the scale of operations, the need for nonmarketing expertise increases as nonmarket instability increases. Just as external market instability increases the need for marketing expertise, internal organization instability increases the need for nonmarketing expertise (Dewar and Hage 1978). For example, rapid growth (or dramatic downsizing) creates organization instability and the need for nonmarketing expertise involving hiring, restructuring, training, contracting, operations, support functions, and so on. Despite the reason, such changes require more nonmarketing expertise. Hence, we expect firms that are making large changes in their labor forces to place a high value on nonmarketing expertise. Hypothesis $1 b^{*}$ follows:

HYPOTHESIS 1B*. Controlling for the scale of operations, firms with greater organization instability (e.g., large changes in number of employees) have a greater need for nonmarketing expertise to manage this instability.

Top management skills should reflect both marketing and nonmarketing expertise. In some environments, their expertise should be mainly marketing. In other environments, nonmarketing expertise should be dominant. When a resource constraint exists on total expertise (marketing plus nonmarketing), then increasing nonmarketing expertise requires a reduction in marketing expertise. Conceptually, firms maximize profits that depend on levels of marketing and nonmarketing expertise, given a resource constraint on total (marketing plus nonmarketing) expertise. When the constraint is binding, then marketing expertise declines at the margin as nonmarketing expertise becomes more important. ${ }^{9}$ With unconstrained resources, the proportion of expertise still depends on the relative importance of

\footnotetext{
${ }^{9}$ See the empirical section for a discussion of constraints.
} 
marketing and nonmarketing expertise. Hypothesis $1 \mathrm{~b}$ follows.

HypOTHESIS 1B. Controlling for the scale of operations, firms with greater organization instability (e.g., large changes in the number of employees) have a smaller need for marketing expertise.

We now move to the second condition. Our second condition implies that EVMEU increases when $\Pi_{\iota}\left(\iota^{*}\left(I_{h}\right)\right.$, $\left.I_{h}\right) / S$ increases. We refer to this condition as the profit impact of marketing expertise.

For example, suppose that marketing expertise generates 100 units in additional sales. If our profit margin on those additional units were zero, marketing expertise would have little value. If our profit margin were large, however, selling these 100 units would be very profitable and marketing expertise would be very valuable. Proposition 2 follows.

PROPOSITION 2. Marketing expertise is more valuable when the expected potential profit margins $\Pi_{\underline{L}}(\dot{-},-\dot{-}) / S$, given perfect marketing expertise, are proportionally greater.

A distinct market advantage usually generates greater profit potential for the firm (Day and Wesley 1988, Carroll 1982, Porter 1980). A superior market performance, such as large market share or high profitability, controlling for the scale of operations, demonstrates some market advantage (Day and Wensley 1988). Here, we do not want to make any causality judgments. One can correctly claim that marketing expertise creates market advantage. We only argue, that firms with a distinct market advantage have greater profit potentials, and that increases the profit impact of marketing decisions. Hypothesis 2a follows:

HYPOTHESIS 2A. Controlling for the scale of operations, firms with a greater market advantage (e.g., higher return on equity, larger market share) have a greater return from marketing expertise because marketing decisions have a greater profit impact.

It is also possible to measure $\Pi_{t}(\cdot, \cdot)$ indirectly by examining market competition. Economic theory suggests that firm profits decrease as market competition increases. Generally, economic theory suggests that firms have less marginal return to marketing activities as competition increases (Hauser and Shugan 1983).
Also, greater competition requires more nonmarketing expertise for making the organization and production processes more efficient because prices become the driving force in the industry (Levitt 1983). Competition encourages cost cutting, and reduces the relative profit impact of marketing decisions. ${ }^{10}$ Hypothesis $2 b$ follows:

HYPOTHESIS 2B. Controlling for the scale of operations, firms with less competition (e.g., fewer competitors, less entry) need greater marketing expertise because marketing decisions have a greater profit impact.

Finally, Condition 3 implies Proposition 3.

PROPOSITION 3. Marketing expertise is more valuable when the performance of the firm's current strategy $\iota_{*}$ could be significantly inferior to the potential performance of the best strategy i* with perfect marketing expertise.

Proposition 3 represents traditional downside risk or the potential loss from a marketing mistake. If the firm's current strategy, $\iota_{*}$, is greatly inferior in the true state $l_{T}$, or other possible states, there is a substantial potential loss from the firm's current strategy $\iota_{*}$. Of course, the firm chooses $\iota_{*}$ because these disastrous states seem unlikely. It is exactly this situation that greatly increases the value of marketing expertise. Marketing expertise insures against these unlikely but disastrous states.

Consider, for example, Coca Cola changing the formula associated with its flagship cola brand. This change risks enormous brand-name capital. A small share loss could generate substantial losses in profit. If a firm has a greater market share or market presence, the firm has more to lose from marketing mistakes. For this reason, firms are very careful who they select to run their "bread-and-butter" business units.

Thus, when the potential loss (e.g., $\Pi_{\iota}\left(\iota^{*}\left(l_{h}\right), l_{h}\right) /$ $\left.\Pi_{\iota}\left(\iota_{*}, l_{h}\right)\right)$ is larger, ceteris paribus, marketing expertise is more valuable. The ratio $\Pi_{\iota}\left(\iota^{*}\left(l_{h}\right), l_{h}\right) / \Pi_{t}\left(\iota_{*}, l_{h}\right)$ is large, controlling for the scale of operations, when the firm's current strategy, without marketing expertise,

\footnotetext{
${ }^{10}$ One can also take the opposing view and argue that, especially for noncommodity-type products, just as efficient organization and production help lower cost, effective marketing can help raise prices and profits by differentiating the product (Associate Editor). These opposing views on the impact of competition on the value of marketing expertise will be resolved by the empirical analyses.
} 
causes loses in market position under some state $l_{h}$. That is, $\Pi_{t}\left(\iota_{*}, l_{h}\right)$ is less than $\Pi_{t}\left(\iota^{*}\left(l_{h}\right), l_{h}\right)$ for an anticipated action. Of course, to lose substantial market position, the firm must have substantial market presence. ${ }^{11} \mathrm{Hy}$ pothesis 3a follows.

HYPOTHESIS 3A. Controlling for the scale of operations, firms with greater market presence (e.g., higher sales) have greater need for marketing expertise because these firms have a greater potential loss from a marketing mistake.

Similar to Proposition 3, Equation (12) implies that, controlling for the scale of operations, nonmarketing expertise is more valuable when the performance of the firm's current nonmarketing strategy $\psi_{*}$ could be significantly inferior to the performance potential of the best nonmarketing strategy $\psi^{*}$ with perfect nonmarketing expertise. Greater market presence might imply the need for a larger organization (e.g., larger assets, more employees, more departments, etc.). Controlling for the scale of operations, larger organization size could also imply greater losses from a mistake. With greater potential losses from organization mistakes, emphasis on management of the organization implies a greater value for nonmarketing expertise (Daft and Steers 1986). Hypothesis $3 b^{*}$ follows.

HYPOTHESIS 3B*. Controlling for the scale of operations, firms with larger organization size (e.g., larger assets) have a greater need for nonmarketing expertise to manage the larger organization.

As the value of nonmarketing expertise increases, the relative value of marketing expertise decreases. Hence, Hypothesis $3 \mathrm{~b}$ follows:

HYPOTHESIS 3B. Controlling for the scale of operations, firms with larger organization size (e.g., larger assets) have a smaller need for marketing expertise.

Note that we can find many good measures of organization size other than the size of assets. It is also possible to assess the need for nonmarketing expertise with measures other than organization size. Fortunately,

\footnotetext{
"This may not be true for start-up companies because even a minor mistake might imply bankruptcy. Hence, $\left.\Pi_{i}\left(\iota_{* *}\left(l_{h}\right), l_{h}\right) / \Pi_{i}\left(\iota_{*}, l_{h}\right)\right)$ is infinite. We consider this issue in our empirical analysis.
}

other measures that we explored were highly correlated with the reported measures. Therefore, our reported measures seem to capture the underlying factor. However, we need future research to study in detail the types of nonmarketing expertise and additional measures for each type.

Note that each proposition has a direct measure (Hypotheses $3 a$ ) and an indirect measure (Hypothesis $3 b$ ). The indirect measure corresponds to the expected value of marketing expertise relative to non-marketing expertise. Hence, nonmarketing expertise is somewhat of an opportunity cost for marketing expertise, at least, in relative terms. Here, more organization instability, more competition, and larger organization size require more nonmarketing expertise to better manage the organization.

\section{Empirical Analysis}

The previous section formulates hypotheses that predict how specific factors should influence the value of marketing expertise. For example, we predict that as market presence (e.g., measured in sales) increases, the value of marketing expertise should increase because the potential loss from a marketing mistake increases.

This section tests our hypotheses. We start by developing measures for marketing expertise. These measures become our dependent variables. Our model predicts how specific variables (e.g., new products, market share, competition, sales, etc.) should influence the value of marketing expertise. These firm and market variables become our independent variables that we use to predict the need for marketing expertise. Hence, we predict which firms should have more marketing expertise from our independent variables. Our goal is to learn whether we can actually predict which firms investment more in marketing expertise.

Our analysis uses the previously developed measures. We again emphasize that additional measures are possible for our underlying factors. Many of these additional measures, however, should be highly correlated with the measures we adopt.

We start by describing our data base. Next, we describe our dependent and independent variables. Finally, we estimate the relationships between our dependent and independent variables. 


\subsection{The Data}

We obtained the data for this study from publicly available sources, such as Forbes, Fortune, and Business Week magazines, Who's Who in America, other financial publications and Survey of Marketing Research (Kinnear and Root 1990). It follows that our measures are objective and the results of our study can be easily replicated.

Our data base included the firms listed in Forbes Top 800 Executives (Forbes, May 28, 1990). We include only established companies in our sample. Missing information forced deletion of several companies. We were left with 592 companies belonging to 53 different industries, as classified by Forbes (Forbes, April 30, 1990). These classifications place each firm in a single primary industry.

Our goal is to identify both firm and market factors, so our variables are at both the firm level (e.g., assets) and industry level (e.g., intensity of competition). These variables are either dependent or independent. Our dependent variables describe the value a firm places on marketing expertise. Our independent variables should explain whether a firm places high value on marketing expertise.

\subsection{Dependent Variables}

We used multiple measures for the value of marketing expertise to capture its different aspects. Our measures are percent of sales spent on marketing research and Chief Executive Officer's (CEO) professional background. These measures should be sufficiently distinct to test our underlying theory.

We assume that firms' spending levels, on various marketing activities, reflect the firms' perceived importance of those activities. For example, firms that spend a larger portion of their sales on marketing research perceive marketing research as more important than do firms spending a smaller portion. Of course, this assumption may be a poor approximation when a firm faces severe financial constraints. That firm may be unable to do market research despite the importance the firm places on marketing research. Here, although our model is correct, our empirical analysis might not detect significant relationships.

Section 3 states that if there exists a resource constraint on total expertise (marketing plus nonmarketing), then increasing nonmarketing expertise requires reducing marketing expertise. The constraint is obviously binding for CEO's background-there can be only one CEO. For marketing research effort, an overall budgetary constraint could apply to marketing and nonmarketing discretionary spending. Here, however, a binding constraint is less often applicable. Perhaps, across firms and industries, all else equal, greater importance of nonmarketing expertise tends to imply lower discretionary spending on marketing researchthe aggregate effect requires that the constraint is binding for only some fraction of the firms (Associate Editor). Binding or not, more market research spending may suggest a greater importance placed on marketing expertise.

The following two dependent variables measure how firms perceive the value of marketing expertise.

\subsubsection{Dependent Variable I: Percent of Sales Spent} on Marketing Research. As the EVMEU increases, firms should spend more on marketing activities, such as marketing research. It follows that the value of marketing expertise should reflect the firm's marketing research expenditures. We therefore used percent of sales spent on marketing research as one of our measures of the firm's perceived value of marketing expertise.

We recognize that firms use other sources for market information beyond market research studies, such as reports from salespeople. Unfortunately, salesforce activities and firms' salesforce spending are highly sensitive information, and no public data sources are available on these variables. A poor measure of marketing expertise could diminish the significance of our empirical relationships. However, we hope market research expenditures are highly correlated with other activities involved with monitoring markets.

Kinnear and Root (1990) report the mean market research expenditures in 1988 for eight industry groups (consumer goods manufacturers, industrial goods manufacturers, advertising agencies, retailing / wholesaling, financial services, health services, publishers/broadcasters, and all others). Although our hypotheses are at the firm level, we use these data. Our literature review failed to identify any sources of more disaggregate information on market research spending. We therefore use the mean market research spending in an industry group for all the firms in that industry group. More 
PAŞA AND SHUGAN

The Value of Marketing Expertise

Table 1 CEO Summary Statistics by CEO Background

\begin{tabular}{|c|c|c|c|c|c|c|c|}
\hline Background of CEO & Years with Firm & Years as CEO & $\begin{array}{c}\text { Salary } \\
(\$ 000 \text { 's })\end{array}$ & Background of CEO & Years with Firm & Years as CEO & $\begin{array}{c}\text { Salary } \\
\text { (\$000's) }\end{array}$ \\
\hline Marketing & 22.2 & 8.1 & $1,698.1$ & Insurance & 25.6 & 9.0 & $1,596.3$ \\
\hline Sales & 31.2 & 9.8 & $1,641.4$ & Legal & 19.1 & 7.8 & $1,143.7$ \\
\hline Retailing & 28.8 & 12.5 & $1,462.7$ & Technical & 26.0 & 7.0 & $1,382.5$ \\
\hline Financial & 19.3 & 8.1 & $1,108.0$ & Operations & 27.5 & 6.9 & $1,349.5$ \\
\hline Banking & 20.9 & 6.9 & 823.7 & Administration & 22.8 & 10.9 & $2,176.0$ \\
\hline Investment & 20.7 & 11.0 & $1,898.9$ & Journalism & 29.8 & 9.8 & $1,080.0$ \\
\hline
\end{tabular}

accurate firm-level measures for this dependent variable should provide better results.

Errors in company sales might produce a bias because we used sales on both sides of the equation. However, we can reasonably assume that our measure of company sales is without error.

4.2.2. Dependent Variable II: Chief Executive Officer's Background. The marketing literature often recommends that firms emphasize marketing expertise. However, measuring actual firm emphasis is difficult. Despite their emphasis, firms like to claim a strong marketing emphasis (Simon and Button 1990). We know of no firms that state they ignore the market.

Often, whether a firm is market-oriented depends on individual perspective. The firm itself may feel it heeds the market. Outside observers may disagree. Hence, we need an objective measure of a firm's emphasis. The measure should be independent of individual perspective.

Extensive measurement via in-depth interviews and surveys can reveal true orientation of specific companies. Narver and Slater (1990) use this tedious and intricate procedure for one company. Replicating this elaborate procedure to obtain this level of detail for hundreds of companies is virtually impossible. We require measures obtainable for hundreds of companies. Besides being objective and practical, our measures of firm emphasis should be replicable. It should be possible for future research to replicate our analysis with different industries, different market factors, and different time periods.

Many researchers (Argysis 1965; Deshpande and Webster 1989; Dumaine 1990; Felton 1959; Levitt 1969; Webster 1988, 1981) verify the critical role played by the
CEO in establishing a firm's area of expertise. These researchers suggest that the CEOs exemplify the firm's orientation. Hence, the CEO's professional background is a possible measure of both the CEO's expertise and the firm's emphasis on different areas of expertise.

To be practical, the CEO's professional background should be measurable. If the CEOs' backgrounds were often inter-disciplinary, our measure could not distinguish between different areas of expertise. Our empirical analysis, however, suggests that most CEOs have backgrounds in one specific discipline. Hence, CEO background is unambiguous and enables business publications to classify CEOs by background.

If the firm's CEO has a marketing background, then we say the firm perceives marketing expertise as very valuable. We doubt that a marketing $\mathrm{CEO}$ alone causes a firm to cherish marketing expertise. We also doubt that firms placing a high value on marketing expertise always have marketing CEOs. Fortunately, we require neither condition for our analysis. It is unimportant to our analysis the direction of causality. A marketing CEO may make a firm value marketing expertise, or a firm valuing marketing expertise may choose a marketing $\mathrm{CEO}$. We only require that firms who, on average, have a marketing $\mathrm{CEO}$ place a higher value on marketing expertise. The marketing CEO may result from either the existing influence of marketing or a desire to increase the influence of marketing.

We obtained CEO backgrounds from the Forbes Top 800 Executives (Forbes, May 28, 1990). Forbes identifies 12 different backgrounds (marketing, sales, retailing, financial, banking, investment, insurance, legal, technical, operations, administration, and journalism). As a cross-check, we verified CEO backgrounds with 
PAŞA AND SHUGAN

The Value of Marketing Expertise

Table 2

RATIO by Industry

\begin{tabular}{llll}
\hline \multicolumn{1}{c}{ Industry } & RATIO & & RATIO \\
\hline Aerospace \& Defense & 0.00 & Regional Banks & 0.02 \\
Industrial Services & 0.38 & Thrift Institutions & 0.03 \\
Business Supplies & 0.57 & Beverages & 0.33 \\
Heavy Equipment & 0.09 & Food Processors & 0.48 \\
Chemicals-Diversified & 0.36 & Tobacco & 0.60 \\
Chemicals-Specialized & 0.14 & Packaging & 0.40 \\
Computers \& Communication-Hardware & 0.24 & Paper \& Lumber & 0.25 \\
Computers \& Communication-Software & 0.13 & Drugs & 0.22 \\
Computers \& Communication-Telecommunication & 0.05 & Health Care Services & 0.00 \\
Construction & 0.08 & Medical Supplies & 0.50 \\
Consumer Durables-Appliances & 0.58 & Insurance-Diversified & 0.00 \\
Consumer Durables-Autos \& Trucks & 0.43 & Insurance-Life \& Health & 0.13 \\
Consumer Durables-Automotive Parts & 0.27 & Insurance-Property \& Casualty & 0.27 \\
Consumer Nondurables-Personal Products & 0.61 & Cement \& Gypsum & 0.25 \\
Consumer Nondurables-Photo \& Toys & 0.40 & Nonferrous Metals & 0.22 \\
Electric Utilities & 0.05 & Steel & 0.33 \\
Gas Producers \& Pipelines & 0.09 & Other Materials & 0.10 \\
Integrated Gas & 0.20 & Retailing-Apparel & 0.71 \\
International Oil & 0.17 & Retailing-Department Stores & 0.78 \\
Oil-field Services & 0.00 & Retailing-Drug \& Discount & 0.60 \\
Other Oil \& Gas & 0.06 & Retailing-Specialty & 0.50 \\
Broadcasting & 0.25 & Retailing-Supermarkets-Convenience & 0.94 \\
& 0.25 & Railroads & 0.17 \\
Publishing & 0.35 & Trucking \& Shipping & 0.25 \\
Brokerage \& Commodities & 0.17 & Airlines & 0.43 \\
Lease \& Finance & 0.00 & Hotels \& Gaming & 0.00 \\
Multinational Banks & 0.10 & & \\
\hline & & & \\
\hline
\end{tabular}

RATIO: Percent of firms with marketing CEOs

employment histories in Who's Who in America (1989). Most backgrounds were accurate. In some cases, the Who's Who in America (1989) background was more accurate than Forbes.

Table 1 contains CEO background information. Marketing background receives the third highest compensation behind administration and investment backgrounds. Banking had the lowest paid CEOs. Marketing CEOs rank fifth in both tenure with company and tenure as CEO.

Table 2 shows the concentration of marketing CEOs (RATIO) by industry. To calculate RATIO, we grouped the first three classes of backgrounds (marketing, sales, and retailing) together. Then we divided the number of CEOs in an industry belonging to this group by the total number of CEOs in that industry. For any given industry, the following formula defines RATIO:

$$
\mathrm{RATIO}^{i} \triangleq\left(\mathrm{CEO}_{\text {marketing }}^{i}+\mathrm{CEO}_{\text {sales }}^{i}+\mathrm{CEO}_{\text {retail }}^{i}\right) / \mathrm{CEO}_{\text {total }}^{i}
$$

where

RATIO $^{i}=$ the ratio variable for industry $i$, $\mathrm{CEO}_{j}^{i}=$ the number of CEO's in group $j$ industry $i$, $j \in\{$ marketing, sales, retailing, total\}.

Consumer nondurables and retailing have the highest RATIOs. These industries traditionally place a high value on marketing expertise. Aerospace and defense, oil field services, lease and finance, health care services, diversified insurance, and hotels and gaming industries have no marketing CEOs (RATIO is zero). These 
industries usually emphasize production and operations more than marketing.

Our dependent variable, CEO background, is a dichotomous measure ( 1 if CEO has a marketing, sales or retailing background; 0 otherwise). It is the probability of a firm having a marketing CEO.

Table 3 summarizes our dependent variables.

\subsection{Independent Variables}

Firm and market variables in this group represent various dimensions of market instability, the profit impact of marketing decisions, and the potential loss from marketing mistakes. These variables differ by firm and industry. Note that our goal is to identify firm and market factors that have an impact on the value of marketing expertise, not to identify industries per se. Data sources for these variables include Business Week (January 8, 1990), Forbes (May 1, 1989; January 8, 1990; April 30, 1990), Fortune (December 4, 1989-April 23, 1990), Marketing News (May 14, 1990), and the Almanac of Business and Industrial Financial Ratios (Troy 1990).

Table 4 lists the independent variables in our final analysis. For each independent variable, Table 4 shows the underlying factor, our definition and the specific measure we used in our empirical analyses.

\subsection{Hypotheses Tests}

Our goal is to identify firm and market conditions that make marketing expertise more valuable to a firm. In other words, our goal is to identify when marketing expertise is more important than other expertise.

To test our hypothesized relationships, we regress our expertise variables (Market Research Spending as Percent of Sales and CEO Background) on the variables in Table 4. We use a multiple regression model for our first dependent variable and a simple logit model for the second. Table 5 and Table 6 provide our results.

Table 5 shows the regression of marketing research spending on our independent variables. The regression produced a $F$-statistic significant at the 0.000 level and an $R^{2}$ of $23.5 \%$. We also see that seven of our eight firm and market variables (New Products, Employee Change, Return on Equity, Market Share, Intensity of Competition, Competitive Entry, and Sales) were significant at least at the 0.05 level. Note that five variables were significant at the 0.01 level. With the exception of one variable (i.e., market share), we find general sup-
Table 3 Dependent Variables (Marketing Expertise)

\begin{tabular}{ccc}
\hline Definition & Dependent Variable & \multicolumn{1}{c}{ Measure } \\
\hline $\begin{array}{l}\text { Value of Marketing } \\
\text { Expertise }\end{array}$ & $\begin{array}{c}\text { Spending on gathering } \\
\text { market information }\end{array}$ & $\begin{array}{c}\text { Annual marketing } \\
\text { research spending as } \\
\text { percent of dollar }\end{array}$ \\
& Role of marketing in & cE0's professional \\
firm & background \\
& (1 if CEO has \\
& marketing, sales or \\
& retailing background; \\
& 0 otherwise $)$ \\
\hline
\end{tabular}

port for our hypotheses. For example, the analysis showed that marketing expertise is more valuable for firms with high sales in industries with many new product introductions, while it is less valuable in more competitive industries with high entry.

Table 5 shows the logit analysis of marketing expertise (measured by CEO background) on our independent variables. The analysis produced a log-likelihood of -247.96 and a hit ratio $(n=592)$ of $82.8 \%$. We also see that four of our eight firm and market variables (New Products, Employee Change, Intensity of Competition, and Assets) were significant at least at the 0.10 level.

Table 7 summarizes our findings. The empirical analyses provide support for our hypotheses. We find that market advantage, competitive entry, and market presence (for CEO background), and organization size (for marketing research spending) do not significantly affect marketing expertise. However, we find that market instability, organization instability, and intensity of competition significantly affect a firm's investment in marketing expertise (both marketing research spending and CEO background).

Greater market instability and market presence (for marketing research spending) increase the value of marketing expertise while higher organization instability, larger organization size (for CEO background) and competition decrease the value of marketing expertise.

It is surprising that as competition increases, the value of marketing expertise decreases. This finding contradicts the relationship hypothesized by Kohli and Jaworski (1990). It is consistent with some conclusions 
PAŞA AND SHUGAN

The Value of Marketing Expertise

Table 4 Independent Variables (Factors Influencing Value of Marketing Expertise)

\begin{tabular}{|c|c|c|c|}
\hline Factor & Definition & Independent Variable & Measure \\
\hline \multirow[t]{2}{*}{ Instability } & Market Instability & New Products & $\begin{array}{l}\text { New product mentions in Forbes, Business Week, Fortune, Marketing News } \\
\text { in past } 12 \text { months }\end{array}$ \\
\hline & Organization Instability & Employee Change & Absolute change in number of employees in past 12 months (\%) \\
\hline \multirow[t]{4}{*}{ Profit Impact } & Market Advantage & Return on Equity & Return on equity $(\%)$ \\
\hline & & Market Share & Share of industry dollar sales $(\%)$ \\
\hline & Competition & Intensity & Number of Forbes 500 firms in industry \\
\hline & & Entry & Change in number of firms in last 5 years $(\%)$ \\
\hline \multirow[t]{2}{*}{ Potential Loss } & Market Presence & Sales & Annual sales $(\$)$ \\
\hline & Organization Size & Assets & Assets $(\$)$ \\
\hline
\end{tabular}

of the DEFENDER model (Hauser and Shugan 1983). As competition increases, the firm's potential profits decrease, and the firm responds by decreasing its marketing expenditures. Marketing expertise is more valuable when there are many possible strategies and some generate high profits.

The negative effect of competition on the value of marketing expertise appears strong. This suggests a fal-

Table 5 Regression Model on Marketing Research Spending

Dependent Variable: Percent of Sales Spent on Marketing Research Independent Variables: Instability, Profit Impact and Potential Loss Measures

\begin{tabular}{lrr}
\multicolumn{1}{c}{ Variable } & Coefficient & $t$-statistic \\
\hline Constant & 26662.410 & $5.323^{\mathrm{a}}$ \\
New Products & 2077.507 & $5.332^{\mathrm{a}}$ \\
Employee Change & -971.794 & $-1.961^{\mathrm{b}}$ \\
Return on Equity & 415.930 & $2.630^{\mathrm{b}}$ \\
Market Share & -34839.912 & $-2.032^{\mathrm{b}}$ \\
Intensity of Competition & -580.838 & $-7.297^{\mathrm{a}}$ \\
Competitive Entry & -34449.408 & $-7.534^{\mathrm{a}}$ \\
Sales & 0.536 & $2.593^{\mathrm{b}}$ \\
Assets & -0.097 & $-1.142^{\mathrm{b}}$ \\
\hline
\end{tabular}

$R^{2}=23.5 \%$.

Adjusted $R^{2}=22.3 \%$.

F-statistic $=19.5$.

$p$-value $=0.000$.

${ }^{a}$ Significant at 0.001 level.

' Significant at 0.01 level.

'Significant at 0.05 level.

${ }^{a}$ Not significant. lacy in the general perception that recently unregulated firms (e.g., banks) have become more market-oriented after deregulation (Pare 1990) due to increased competition. These firms may have increased their investments in marketing expertise after deregulation. However, our findings suggest increased competition did not cause of these increased investments. Our findings suggest that deregulation creates turbulent markets and

\section{Table 6 Logit Model on CEO Background}

Dependent Variable: CEO Background ( 1 if marketing, 0 otherwise) Independent Variables: Instability, Profit Impact and Potential Loss Measures

\begin{tabular}{lrr} 
Variable & Coefficient & $t$-statistic \\
\hline Constant & -0.75434 & $-2.281^{\mathrm{b}}$ \\
New Products & 0.28066 & $7.819^{\mathrm{a}}$ \\
Employee Change & -1.11440 & $-1.361^{\mathrm{c}}$ \\
Return on Equity & 0.00614 & $0.556^{\mathrm{d}}$ \\
Market Share & -0.06839 & $-0.099^{\mathrm{d}}$ \\
Intensity of Competition & -0.03853 & $-5.023^{\mathrm{a}}$ \\
Competitive Entry & -0.20919 & $-0.623^{\mathrm{d}}$ \\
Sales & 0.00002 & $0.895^{\mathrm{d}}$ \\
Assets & -0.00002 & $-1.561^{\mathrm{c}}$ \\
\hline
\end{tabular}

Log-Likelihood $=-247.96$.

Maddala $R^{2}=21.0 \%$.

Hit Ratio $(n=592)=82.8 \%$.

a Significant at 0.001 level.

${ }^{\circ}$ Significant at 0.025 level.

${ }^{c}$ Significant at 0.100 level.

${ }^{d}$ Not significant. 
Table 7 Hypothesis Test Results

\begin{tabular}{|c|c|c|c|c|c|}
\hline \multirow[t]{3}{*}{ Factor } & \multirow[t]{3}{*}{ Definition } & \multirow[t]{3}{*}{ Independent Variable } & \multicolumn{3}{|c|}{ Expected and Found Coefficient Signs } \\
\hline & & & \multirow[t]{2}{*}{ Expected } & \multicolumn{2}{|r|}{ Found } \\
\hline & & & & MR & CEO Background \\
\hline \multirow[t]{2}{*}{ Instability } & Market Instability & New Products & + & + & + \\
\hline & Organization Instability & Employee Change & - & - & - \\
\hline \multirow[t]{4}{*}{ Profit Impact } & Market Advantage & Return on Equity & + & + & $\oplus$ \\
\hline & & Market Share & + & - & $\theta$ \\
\hline & Competition & Intensity & - & - & - \\
\hline & & Entry & - & - & $\ominus$ \\
\hline \multirow[t]{2}{*}{ Potential Loss } & Market Presence & Sales & + & + & $\oplus$ \\
\hline & Organization Size & Assets & - & $\ominus$ & - \\
\hline
\end{tabular}

MR is market research spending.

$\oplus$ indicates positive but not significant.

$\Theta$ indicates negative but not significant.

that turbulence enhances the value of marketing expertise. Our findings also suggest other possible factorssuch as increased market instability due to many new product introductions - that may have caused firms to increase their emphasis on marketing after deregulation. As Pare (1990) reports, banks have been offering many new products and services, mainly through bundling, in an attempt to win more consumer trade. Hence, in addition to being consistent with actual changes after deregulation, our findings also provide a better understanding of the intricate nature of the many factors that firm face.

\section{Implications for Firms}

Our study provides some guidelines about when a firm should invest in marketing expertise, and identifies some conditions under which marketing expertise is more valuable to a firm. Using our model, a firm can begin to investigate whether it should have more or less marketing expertise given the conditions it operates in. This is especially critical when the industry conditions undergo some changes. Firms should look at the impact of these changes on the potential loss from marketing mistakes, the profit impact of marketing decisions, and market instability. Different firm and market variables have different impacts. For example, when market instability increases, due to high number of product introductions in an industry, firms need more marketing expertise.

\section{Future Research}

Our model provides a theoretical framework for the relationship between the expected value of marketing expertise and various firm and market conditions. Our empirical analyses identified several key factors that make marketing expertise more valuable to a firm. Our findings are encouraging, but many challenges remain.

Perhaps efficient and effective measurement is the biggest challenge. We realize that our findings are limited by the extent of our measures and our database. For example, we relied heavily on the market research spending and CEO background as our measures of the value of marketing expertise. One can argue that marketing expertise encompasses many other activities. Our second measure, professional background of CEO, may be somewhat controversial. It would be valuable to do future work looking into different measures of these constructs. We hope that future research can build on our first attempt to quantify these constructs. We believe that developing and using different measures to 
capture the essence of marketing expertise will be a continuing challenge.

We relied on industry figures for some variables due to lack of firm level data. Exploring new data sources to represent all our factors with firm level data will improve our confidence in the results.

Future research should analyze different cross sections of the data, such as firm type (e.g., industrial versus consumer). Any significant differences across groups can be studied. Our goal was to identify firm and market factors that have an impact on the value of marketing expertise, not to identify industries per se. However, extending our analyses to identify industries or industry groups can be valuable.

We did our analyses using U.S. industries. However, European and Asian industries may provide richer examples with clearer distinctions between different areas of expertise.

Future research can explore richer models. Future research could expand our theory to more formally consider competition, continuous probability distributions for the states in each state space, imperfect expertise, regulatory factors, supplier interactions, and different nonmarketing expertise. Dynamic extensions might provide insights on learning and signaling in a competitive environment. It also would be interesting to uncover the relationship between channel instability (Coughlan and Wernerfelt 1989) and the need for marketing expertise.

\section{Summary and Conclusions}

This paper had three objectives: (1) to construct a theoretical model that aids in evaluating marketing expertise, (2) to use that theoretical model to identify factors influencing the value of marketing expertise, and (3) to empirically test the model.

To accomplish the first objective, we use a decisiontheoretic model where firms must choose strategies. The true state-of-the-world determines the profit of a strategy. Expertise identifies the true state-of-the-world. The difference in expected profit between decisions made with and without expertise determines the expected value of expertise.

Using a decision-theoretic model, we calculated the expected value of marketing expertise. Our theoretical model provided the following three factors influencing the expected value of marketing expertise: (1) the instability of the marketing environment, (2) the profit impact of marketing decisions, and (3) the potential loss from marketing mistakes.

An empirical analysis helped accomplish our third objective. We identified some conditions under which marketing expertise is more valuable to a firm. Greater market instability and market presence (for marketing research spending) increase value of marketing expertise, while higher organization instability, larger organization size (for CEO background), and competition decrease the value of marketing expertise.

In formulating strategies for new products, market research, promotion, sales force, advertising, and other activities, the firm must first consider the role of marketing in the complete situation of the firm. Webster (1981) and Day and Wind (1980) note that marketing academicians have been preoccupied by tactical decisions rather than investigating important strategic issues. Researchers now realize that a market expertise and a market orientation may not always be best (Kohli and Jaworski 1990, Houston 1986). Identifying when marketing expertise is valuable for a firm has prominent consequences. This study provides a theoretical and empirical model for tackling the problem. In sum, this research reinforces the emerging view that the firm and market factors have an influence on the value of marketing expertise.

Like other researchers (Kohli and Jaworski 1990, Houston 1986), we argue that marketing expertise may not be the most valuable type of expertise for all firms in all industries. By identifying both theoretically and empirically the conditions under which marketing expertise is more valuable to a firm, we provide a theoretical and empirical model for contrasting the importance of marketing relative to other disciplines. ${ }^{12}$

\footnotetext{
${ }^{12}$ We are grateful to Jehoshua Eliashberg, the Departmental Editor of Marketing, the Associate Editor and four anonymous reviewers for their valuable comments and suggestions. We also thank Gordon Antelman, Mark Bergen, Harry Davis, Shantanu Dutta, Kristiaan Helsen, Abel Jeuland, Mary Sullivan, Osman Zaim, and all Chicago Workshop participants for their valuable comments. The first author is indebted to the Marketing Science Institute for financial assistance via the Alden G. Clayton Award.
} 


\section{Appendix}

ProOf OF CONDITION 1. We defined the strategy $\iota^{*}\left(I_{h}\right)$ that maximizes the payoff for any given state $I_{h}$ as [Equation (7)]:

$$
\iota^{*}\left(I_{h}\right)=\underset{\iota_{1}, \iota_{2}, \cdots}{\operatorname{maximum}} \Pi_{\iota}\left(\iota_{i}, I_{h}\right) .
$$

Assume that $k \in \Phi_{1}$ and $p_{I}\left(I_{k}\right)=1$, then optimal marketing strategy given current marketing expertise [Equation (5)] becomes:

$$
\begin{aligned}
\iota_{*} & =\underset{\iota_{1}, \iota_{2}}{\operatorname{maximum}} \sum_{h \in \Phi_{l}} p_{l}\left(I_{h}\right) \Pi_{\iota}\left(\iota_{i}, I_{h}\right) \\
& =\underset{\iota_{1}, t_{2}}{\operatorname{maximum}} \Pi_{\iota}\left(\iota_{i}, I_{k}\right)=\iota^{*}\left(I_{k}\right) .
\end{aligned}
$$

Expected payoff given the optimal marketing strategy with current marketing expertise [Equation (6)] becomes:

$$
\Pi_{\iota}\left(\iota_{*}\right)=\Pi_{\iota}\left(\iota^{*}\left(I_{k}\right)\right)=\sum_{h \in \Phi_{l}} p\left(I_{h}\right) \Pi_{\iota}\left(\iota^{*}\left(I_{k}\right), I_{h}\right)=\Pi_{\iota}\left(\iota^{*}\left(I_{k}\right), I_{k}\right) .
$$

Expected payoff given perfect marketing expertise [Equation (8)] becomes:

$$
\Pi_{t}=\sum_{h \in \Phi_{l}} p_{l}\left(I_{h}\right) \Pi_{\iota}\left(\iota^{*}\left(I_{h}\right), I_{h}\right)=\Pi_{\iota}\left(\iota^{*}\left(I_{k}\right), I_{k}\right)
$$

Hence, the expected value of perfect marketing expertise given the current level of marketing expertise is [Equation (9)]:

$$
\operatorname{EV}_{\iota}\left(\iota^{*}\left(I_{k}\right)\right)=\Pi_{\iota}-\Pi_{\iota}\left(\iota_{*}\right)=0 .
$$

\section{References}

Aaker, D. A., Strategic Market Management, 2nd Ed, Wiley, New York, 1988.

- Managing Assets and Skills: The Key To Sustainable Competitive Advantage," California Management Review, 31, 2 (1989), 91-106.

Argyris, C., Organization and Innovation, Richard D. Irwin, Homewood, IL, 1965.

Bagozzi, R., "Marketing as Exchange," J. Marketing, 39 (1975), 32-39.

Bernoulli, D., Exposition of a New Theory on the Measurement of Risk, in Commentarii Academiae Scientarum Imperialis Petropolitonae, 5, 175-192. (Translated by L. Sommers, 1954, Econometrica, 22, 2336.)

Boulding, W. and R. Staelin, "Environment, Market Share, and Market Power," Management Sci., 36, 10 (1990), 1160-1177.

Bunn, D., Applied Decision Analysis, McGraw-Hill, New York, 1984.

Capon, N., J. U. Farley, and S. Hoenig, "Determinants of Financial Performance: A Meta-Analysis," Management Sci., 36, 10 (1990), 1143-1159.

Carroll, P. J., "The Link Between Performance and Strategy," J. Business Strategy, 2 (1982), 3-20.

Coughlan, A. T. and B. Wernerfelt, "On Credible Delegation by Oligopolists: A Discussion of Distribution Channel Management," Marketing Sci., 35, 2 (1989), 226-239.

Chernoff, H. and L. E. Moses, Elementary Decision Theory, Wiley, New York, 1959.

Child, J., Organization, Harper \& Row, New York, 1977.
Coggin, W. C., "How the Multidimensional Structure Works at Dow Corning," Harvard Business Review, January-February (1994), 5465.

Cook, V. J., Jr., "Marketing Strategy and Differential Advantage," J. Marketing, 47 (1983), 68-75.

Daft, R. and R. M. Steers, Organizations: A Micro/Macro Approach, Scott, Foresman and Company, Glenview, IL, 1986.

Day, G. S. and R. Wensley, "Marketing Theory with a Strategic Orientation," J. Marketing, 47 (1983), 101-10.

— and - "Assessing Advantage: A Framework for Diagnosing Competitive Superiority," J. Marketing, 52 (1988), 1-20.

- and Y. Wind, "Strategic Planning and Marketing: Time for a Constructive Partnership," J. Marketing, 44 (1980), 7-8.

Deshpande, R. and A. Parasuraman, "Organizational Culture and Marketing Effectiveness," in P. F. Anderson and M. J. Ryan (Eds.), Scientific Methods in Marketing, American Marketing Association, Chicago, IL, 1984, 137-140.

— and F. Webster, "Organizational Culture and Marketing: Defining the Research Agenda," J. Marketing, 53 (1989), 3-15.

Dewar, R. and J. Hage, "Size, Technology, Complexity, and Structural Differentiation: Toward a Theoretical Synthesis," Administrative Sci. Quarterly, 23 (1978), 111-136.

Dumaine, B., "Creating a New Company Culture," Fortune, January $15,1990,127-131$.

Duncan, R., 'What is the Right Organization Structure? Decision Tree Analysis Provides the Answer," Organizational Dynamics, Winter (1979), 429.

Eliashberg, J. and R. Chatterjee, "Analytical Models of Competition with Implications for Marketing: Issues, Findings, and Outlook," J. Marketing Res., 22 (1985), 237-261.

— and J. R. Hauser, "A Measurement Error Approach for Modeling Consumer Risk Preference," Management Sci., 31, 1 (1985), 1-25.

- and R. Winkler, "Risk Sharing and Group Decision Making," Management Sci., 27, 11 (1981), 1221-1235.

— and R. Steinberg, "Marketing-Production Decisions in Industrial Channel of Distribution," Management Sci., 33, 8 (1987), 981-1000.

Felton, A., "Making the Marketing Concept Work," Harvard Business Review, 37 (July-August 1959), 55-65.

Gatignon, H., B. Weitz, and P. Bansal, "Brand Introduction Strategies and Competitive Environment," J. Marketing Res., 27 (1990), 390401.

Gomez-Mejia, L., J. E. McCann, and R. C. Page, 'The Structure of Managerial Behaviors and Rewards," Industrial Relations, 24 (1985), $147-154$.

Hauser, J. R. and D. P. Clausing, "The House of Quality," Harvard Business Review, 66, 3 (1988), 63-73.

_ and S. M. Shugan, "Defensive Marketing Strategies," Marketing Sci., 2, 4 (1983), 319-360.

Houston, F., "The Marketing Concept: What It Is and What It Is Not," J. Marketing, 50 (1986), 81-87.

Keeney, R., "Decision Analysis: An Overview," Oper. Res., 30 (1982), 803-838.

Kinnear, T. C. and K. L. Bernhardt, Principles of Marketing, 2nd Ed., Scott, Foreman \& Company, Glenview, IL, 1986. 
PASA AND SHUGAN

The Value of Marketing Expertise

Kinnear, T. C., K. L. Bernhardt, and A. R. Root, 1988 Survey of Marketing Research: Organization, Functions, Budget, Compensation, American Marketing Association, Chicago, IL, 1990.

Kohli, A. K. and B. J. Jaworski, "Market Orientation: The Construct, Research Propositions, and Managerial Implications," J. Marketing, 54 (1990), 119

Kotler, P., Marketing Management: Analysis, Planning, and Control, 4th Ed., Prentice-Hall, Englewood Cliffs, NJ, 1984.

_. "A Generic Concept of Marketing," J. Marketing, 36 (1972), 4654.

Levitt, T., "The Globalization of Markets," Harvard Business Review, 61 (1983), 92-102.

- The Marketing Mode, McGraw-Hill, New York, 1969.

Lilien, G. and E. Yoon, "The Globalization of Markets," Harvard Business Review, 61 (1990), 92-102.

Luce, R. D. and H. Raiffa, Games and Decisions, Wiley, New York, 1957.

McNamara, C. P., 'The Present Status if the Marketing Concept," J. Marketing, 36 (1972), 50-57.

Marquis Who's Who in America (1988-1989), 45th Ed., MacMillan Directory Division, National Register Publishing Company, Glenview, IL: 1988-1989.

Marschak, J. and R. Radner, Economic Theory of Teams, Yale University Press, New Haven, CT, 1972.

McCarthy, E. J. and W. D. Perreault, Jr., Basic Marketing: A Managerial Approach, 8th Ed., Richard D. Irwin, Inc., Homewood, IL, 1984.

Mintzberg, H., The Structuring of Organizations, Prentice-Hall, Englewood Cliffs, NJ, 1979.

Narver, J. C. and S. F. Slater, "The Effect of a Market Orientation on Business Profitability," J. Marketing, 54 (1990), 20-35.

Pare, T. P., "Banks Discover the Consumer," Fortune, February 12 1990, 96-104.

Porter, M. E., Competitive Strategy: Techniques for Analyzing Industries and Competitors, The Free Press, New York, 1980.

Raiffa, H., Decision Analysis, Addison-Wesley, Reading, MA, 1968.
Randolph, W. A. and G. G. Dess, "The Congruence Perspective of Organization Design: A Conceptual and Multivariate Research Approach," Academy of Management Review, 9 (1984), 114-127.

Schlaifer, R., Analysis of Decisions under Uncertainty, McGraw-Hill, NY, 1969.

Shapiro, B. P., "What the Hell is 'Market Oriented'?," Harvard Business Review, 66, 6 (1988), 119-125.

Simon, R. and G. Button, "What I Learned in the Eighties," Forbes, January 8, 1990, 100-114.

Springmier, R., "Planning as a Vehicle for Strategic Redirection in a Matrix Structure," in Peter Lorange, Implementation of Strategic Planning, Prentice-Hall, Englewood Cliffs, NJ, 1982.

Steers, R. M., G. R. Ungson, and R. T. Mowday, Managing Effective Organizations: An Introduction, Kent, Boston, MA, 1985.

Troy, L., Almanac of Business and Industrial Financial Ratios, 1990 Ed., Prentice-Hall, Englewood Cliffs, NJ, 1990.

Urban, G. L. and J. R. Hauser, Design and Marketing of New Products, Prentice-Hall, Englewood Cliffs, NI, 1980.

— and S. H. Star, Advanced Marketing Strategy: Phenomena, Analysis, and Decisions, Prentice-Hall, Englewood Cliffs, NJ, 1991.

Webster, F. E., Jr., "Rediscovering the Marketing Concept," Business Horizons, 31 (1988), 29-39.

__, 'Top Management's Concerns About Marketing: Issues for the 1980's," J. Marketing, 45 (1981), 9-16.

Whitley, W., "Managerial Work Behavior: An Integration of Results from Two Major Approaches," Academy of Management J., 28 (1985), 344-362.

Winkler, R. L., An Introduction to Bayesian Inference and Decisions, Holt, Rinehart, and Winston, NY, 1972.

- and W. L. Hays, Statistics: Probability, Inference and Decision, 2nd Ed., Holt, Rinehart, and Winston, NY, 1975.

Zirger, B. J. and M. A. Madique, "A Model of New Product Development: An Empirical Test," Management Sci., 36 (1990), 867883.

Accepted by Jehoshua Eliashberg; received June 1991. This paper has been with the authors 28 months for 4 revisions. 